\title{
An Initial Study of Tree-Adjoining Grammar Formalism for Parsing Manipuri Language
}

\author{
Yumnam Nirmal \\ Department of Computer Science and Engineering \\ Tezpur University \\ Assam 784028, India \\ ynirmal@tezu.ernet.in
}

\author{
Utpal Sharma \\ Department of Computer Science and Engineering \\ Tezpur University \\ Assam 784028, India \\ utpal@tezu.ernet.in
}

\begin{abstract}
We present an initial study into the representation of tree-adjoining grammar formalism for parsing Manipuri language. Being a low resource and computationally less researched language, it is difficult to achieve a natural language parser for Manipuri. Treebanks, which are the main requirement for inducing data-driven parsers, are not available for Manipuri. In this paper, we present an extensive analysis of the Manipuri language structure and formulate a lexicalized tree-adjoining grammar. A generalized structure of Manipuri phrases, clauses and the structure of basic and derived sentences have been presented. The sentence types covered in our analysis are that of simple, compound and complex sentences. Using the tree-adjoining grammar we have formulated, one can implement a Manipuri parser whose results can be of immense help in creating a Treebank for Manipuri.
\end{abstract}

Keywords: Parsing; Tree-adjoining grammar; Tibeto-Burman; Manipuri

\section{INTRODUCTION}

Computational representation of language syntax is a crucial step in achieving parsing of natural languages. It involves representation of natural language syntax into computational formalism such as context-free grammar (CFG), treeadjoining grammar (TAG) and dependency grammar (DG). We can use these computational grammar formalisms along with parsing algorithms to successfully induce a parser.

Tree-adjoining grammar is a formalism introduced by Joshi et al. [1] for describing linguistic structure of natural languages. It is a tree generating and more powerful formalism as opposed to string generating formalisms such as a context-free grammar. A TAG comprises a finite set of elementary trees which are further divided into initial trees $(\alpha)$ and auxiliary trees $(\beta)$. Initial trees have internal nodes labeled with nonterminals, and the leaf nodes are either labeled with terminals or non-terminals with substitution marker $(\downarrow)$. Auxiliary trees, on the other hand, are constrained with such a condition that it should have a non-terminal leaf node (marked with *) exactly same as the root node. Trees corresponding to sentences of a language are generated through a process called 'adjunction'. Adjunction operation inserts an auxiliary tree at a corresponding node of an elementary tree or a derived tree. An advantage of TAG formalism is its ability to handle localized dependencies such as wh-dependency, filler gap and predicate arguments, which are difficult to achieve with CFG.

We explore the use of tree-adjoining grammar (TAG) formalism for representing the syntax of Manipuri language. We use lexicalized approach to tree-adjoining grammar [2] for our work. Lexicalization allows each and every elementary tree to be associated with a lexical item (word), known as anchors (indicated by $\diamond$ ) of the tree.

\section{LITERATURE REVIEW}

Computational tools for Manipuri are non-existent and its resources are hardly available making it a low resource language that can help achieve parsing of the language. Currently, Treebanks are non-existent for this language that could have otherwise helped in developing data-driven parsers. Additionally, developing a significantly sized
Treebank for Manipuri is constrained with a huge amount of time and manpower. This is not viable within a short period of time and the limited resources available.

There has been plenty of work done on parsing of different languages, by utilizing either rule-based or data-driven approaches. These works could not be adapted to Manipuri, as different languages exhibit different behavior in terms of syntax and structure. Though, there exist similarities across languages, it becomes extremely necessary to model the syntax of an individual language, so that its detailed linguistic properties could be captured properly. As an example, English follows subject-verb-object (SVO) pattern, while Manipuri being a Tibeto-Burman language [3] follows subject-objectverb (SOV) pattern. At the phrase level, in English, a determiner always precedes a head noun, whereas in Manipuri, a determiner always succeeds a head noun.

Manipuri also differs from Indian languages such as Hindi and Bangla that belongs to the Indo-Aryan language family. As an example, quantifiers (Qtf) and adjectives (Adj) precede a head noun $(\mathrm{N})$ in Hindi. Whereas, in the case of Manipuri, quantifiers always follow a head noun, while adjectives can either precede or succeed a head noun. These have been illustrated in examples 1 and 2 .

Example 1. (a) Manipuri: $\quad \mathbb{H}_{2} \dot{\mathrm{n}}$ ॠ ஈरेंஈ ə⿹an $\backslash \mathrm{N}$ mjam $\backslash \mathrm{Qtf}$ child many

(b) Hindi: बहुत बच्चे bəhut Qtf bəccelN many children

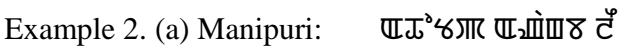
ət ${ }^{\mathrm{h}}$ otpə\Adj ə⿹anbə\Adj ləilN soft red flower

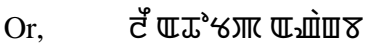
ləilN ət $^{\mathrm{h}}$ otpə\Adj ənaybə\Adj flower soft red 
(b) Hindi: नरम लाल फुल

$$
\begin{aligned}
& \text { nə.əm\Adj lal\Adj } \mathrm{p}^{\mathrm{h}} \mathrm{ul} \mathrm{N} \\
& \text { soft red flower } \\
& \text { * फुल नरम लाल } \\
& \mathrm{p}^{\mathrm{h}} \mathrm{ul \backslash N} \text { nə.əm\} \backslash \text { Adj lal\Adj } } \\
{\text { flower soft red }}
\end{aligned}
$$

There has been no work reported on TAG of Manipuri, other than a preliminary work by Singh and Sharma [4]. The work covers only a few instances of Manipuri phrases and sentences, and does not cover derived sentences. It also lacks generalization in terms of sentence structure. Additionally, domain of locality in relation to word classes, which is a main advantage of using TAG formalism, has not been analyzed in this work.

Another notable works reported on CFG based parsing of Manipuri is that of Nirmal and Sharma [5, 6]. Sarangthem and Singh [7] also reported a work focused on developing an abstract data structure for Manipuri noun phrases.

\section{ELEMENTARY TREES FOR BASIC MANIPURI SENTENCES}

We construct elementary trees for basic structures of Manipuri language by extensively analyzing the language structure. The trees have been derived by studying the existing Manipuri linguistic literature and our native knowledge of the language.

\subsection{Noun Phrase}

Noun phrases (NP) in Manipuri minimally consists a head as the obligatory constituent and can have adjectives, determiners, quantifiers, or locative nouns (NLoc) as its optional constituents [8, 9]. Within an NP, these optional constituents can occur together, but determiners and quantifiers generally do not occur together. The head can be either a noun or a pronoun $(\mathrm{Pr})$ in its pure form without any suffixes, but not verbal nouns (Vn) [7]. Determiners and quantifiers always succeed the head, while adjectives either precede or succeed the head. Adjectives, while constituting an NP along with other optional constituents, always occur as an immediate neighbor of the head. The remaining optional constituents can immediately follow the head, only if adjectives precede the head. Otherwise, adjectives immediately follow the head and other optional constituents follow the adjectives.

Initial trees $(\alpha N)$ and $(\alpha P R)$ in Fig. 1 represent NPs consisting of either a noun or a pronoun without any optional constituent, while $(\alpha N d e t)$ and $(\alpha P R d e t)$ represent NPs constituting a head followed by a determiner. Similarly, $(\alpha N q t f)$ and $(\alpha P R q t f)$ represent NPs constituting a head followed by a quantifier.

In example 3, we illustrate a sentence consisting two NPs. The

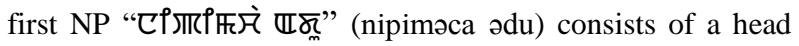
noun succeeded by a determiner, while the second NP "尺्र $P$ ९ઢ" (cəhi təıаməıi) has a quantifier succeeding a head noun. These two NPs can be represented using the initial trees $(\alpha N d e t)$ and $(\alpha N q t f)$ shown in Fig. 1.

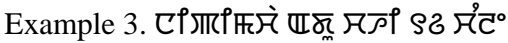

[nipiməcalN ədulDet]NP [cəhilN tə.amərilQtf]NP cəylelV

The girl is approaching 14 years.

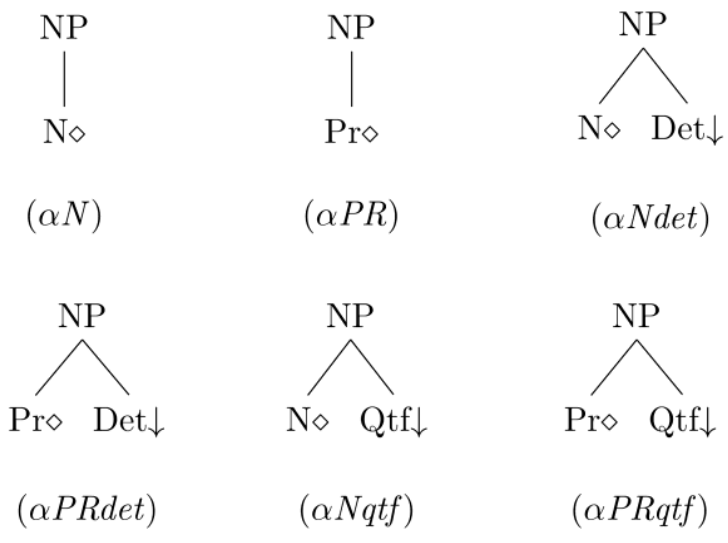

Figure 1. Initial trees for noun phrases

The constitution of quantifiers and determiners along with a pronoun as head in an NP is illustrated in examples 4 and 5 respectively.

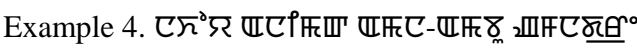

[nək ${ }^{\mathrm{h}} \mathrm{oj} \backslash \mathrm{Pr}$ ənimək।Qtf]NP əmənə-əməbu।Pr ymnədrelV You two are not able to win over each other.

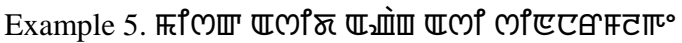

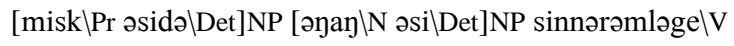
I will hand over the baby to this man.

Manipuri is a post-positional language as opposed to preposition. The post-positions are generally directional and indicate temporal dimensions within a syntactic relation [3]. A post-position, always succeeds the head within an NP, or either succeeds an NP. In Manipuri, post-positions occur as locative nouns (NLoc) and with case markers suffixed to them. Structures of such NPs have been represented with elementary trees $(\alpha N n l o c)$ and $(\beta n p N L O C)$ as shown in Fig. 2. We have marked the NP node in $(\alpha$ Nnloc $)$ with null adjoining $(\mathrm{NA})^{1}$ as it is not allowed to be adjoined by ( $\left.\beta n p N L O C\right)$. Adjoining using ( $\beta n p N L O C)$ is allowed only to NPs of type $(\alpha N),(\alpha P R),(\alpha N d e t),(\alpha P R d e t),(\alpha N q t f)$ and $(\alpha P R q t f)$.

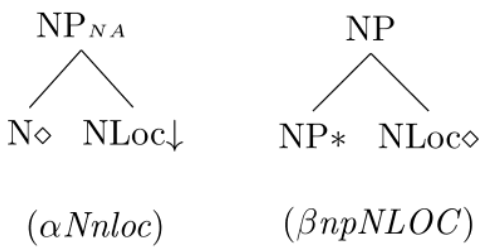

Figure 2. Elementary trees for NPs formed with locative nouns

In example 6, the NP "L్లుగ a head noun followed by a locative noun, whereas in example

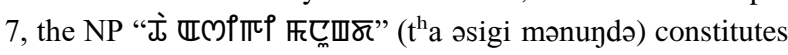
an existing NP followed by a locative noun.

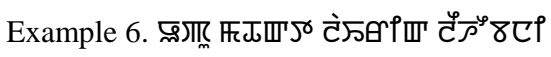

[upulN mot ${ }^{\mathrm{h}} \mathrm{ktəlNLoc]NP}$ ləi.xik ləihəubəni

The book is over the cupboard.

\footnotetext{
${ }^{1}$ A node where adjoining is disallowed is said to have a null adjoining (NA) constraint.
} 


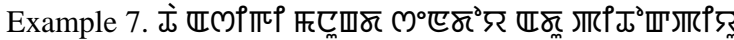
[[ $\mathrm{t}^{\mathrm{h}} \mathrm{a}$ asigi]NP mənuydəlNLoc]NP sendoj ədu pit ${ }^{\mathrm{h}}$ okpiyu Please clear the interest within this month.

\subsection{Auxiliary Trees for Modifying Noun and Pronoun}

Auxiliary trees allow recursion as well as provide a way to introduce modifiers for a word class. We can use these feature of TAG to successfully modify noun and pronoun word classes.

Within an NP in Manipuri, adjectives either precede or succeed the head (noun or pronoun) which is being modified. These can be achieved using auxiliary trees $(\beta A D J n)$, $(\beta n A D J),(\beta p r A D J)$ and $(\beta A D J p r)$ shown in Fig. 3.

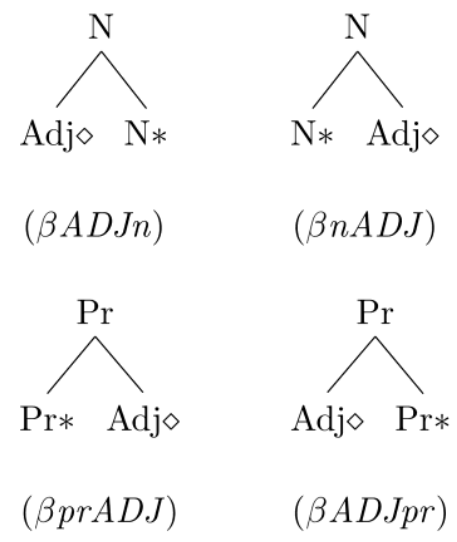

Figure 3. Auxiliary trees for modifying noun and pronoun using adjectives

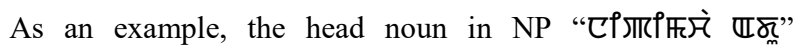
(nipimaca ədu) of example 3 can be modified with the

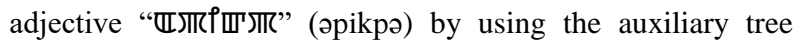
$(\beta A D J n)$, as shown in Fig. 4.
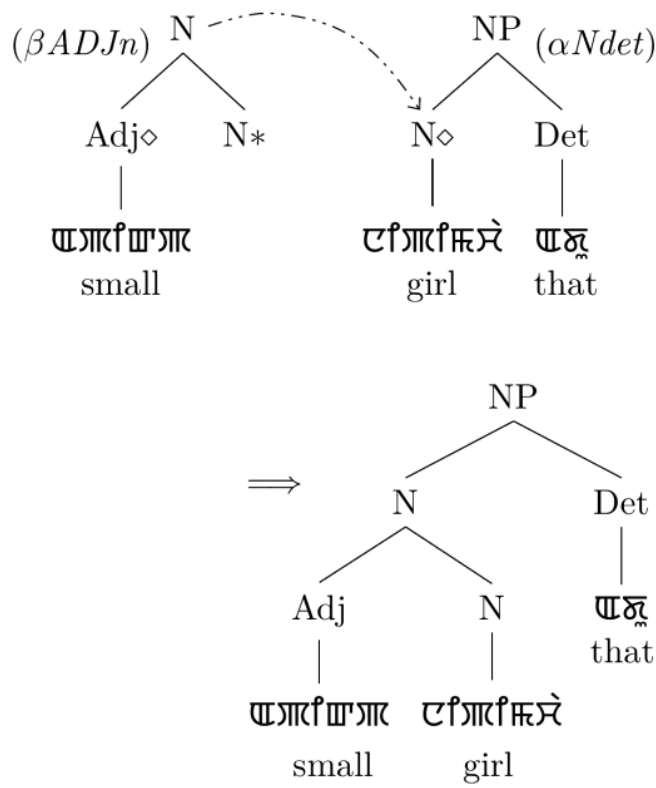

Figure 4. An example of noun modification with adjective in Manipuri

\subsection{Elementary Trees for Basic Sentences}

Manipuri belong to the family of Tibeto-Burman languages [10] and follow subject-object-verb (SOV) order and generally has verb as the final constituent of a sentence [3]. Using sub-categorization information of verbs, we classify the basic sentence structure of Manipuri into three tree families as shown in Fig. 5. The verbs can be of type intransitive, monotransitive and ditransitive. In our further discussions, we denote subject, direct object and indirect object using $\mathrm{NP}_{0}$, $\mathrm{NP}_{1}$ and $\mathrm{NP}_{2}$ respectively.
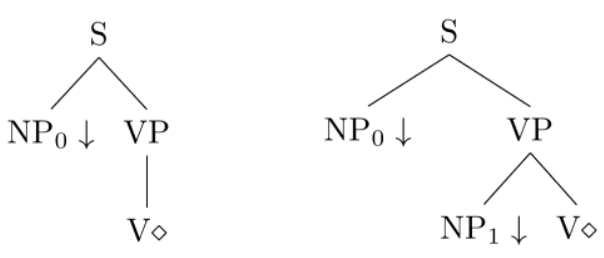

$(\alpha n p 0 V)$

$(\alpha n p 0 n p 1 V)$

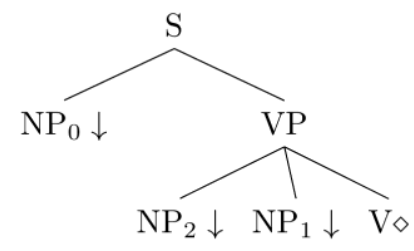

( $\alpha n p 0 n p 2 n p 1 \mathrm{~V})$

Figure 5. Initial trees for basic Manipuri sentences

Sentences with intransitive verbs in Manipuri lack an object and have only the subject followed by a verb [3]. We represent such sentences with the initial tree $(\alpha n p 0 V)$ shown in Fig. 5. We illustrate such a sentence with example 8. The parse tree for this sentence can be formed by substituting

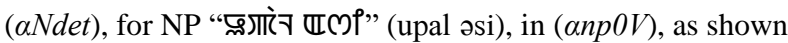
in Fig. 6.

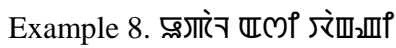

[upallN əsilNLoc] $\mathrm{NP}_{0}$ waynilV

The tree is tall.

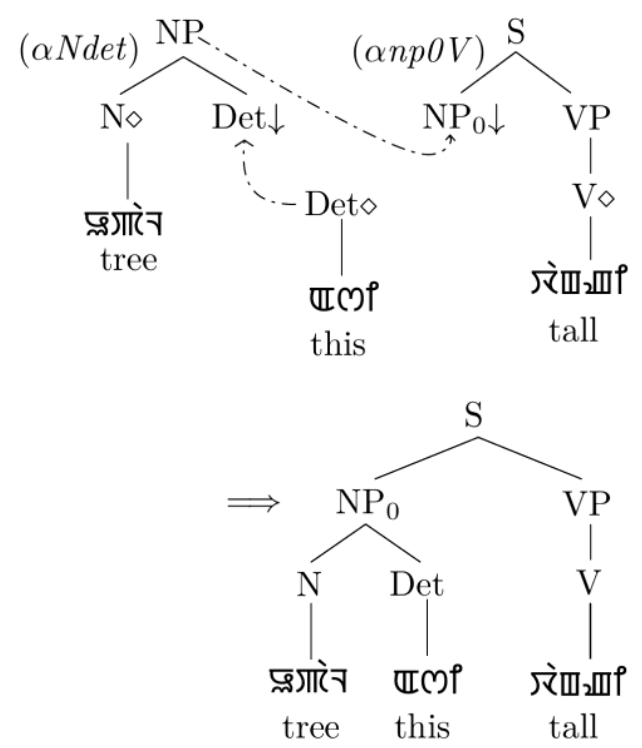

Figure 6. Parse tree formation for example 8 
A monotransitive verb takes a subject and an object as its arguments. And, sentences formed with such verbs do not contain a complement [3]. This type of sentences can be represented using the initial tree (anp0nplV) shown in Fig. 5. One such sentence can be seen in example 3 and its respective parse tree is shown in Figure 7. This tree can be obtained by substituting ( $\alpha N d e t)$ and $(\alpha N q t f)$ in ( $\alpha$ np0nplV).

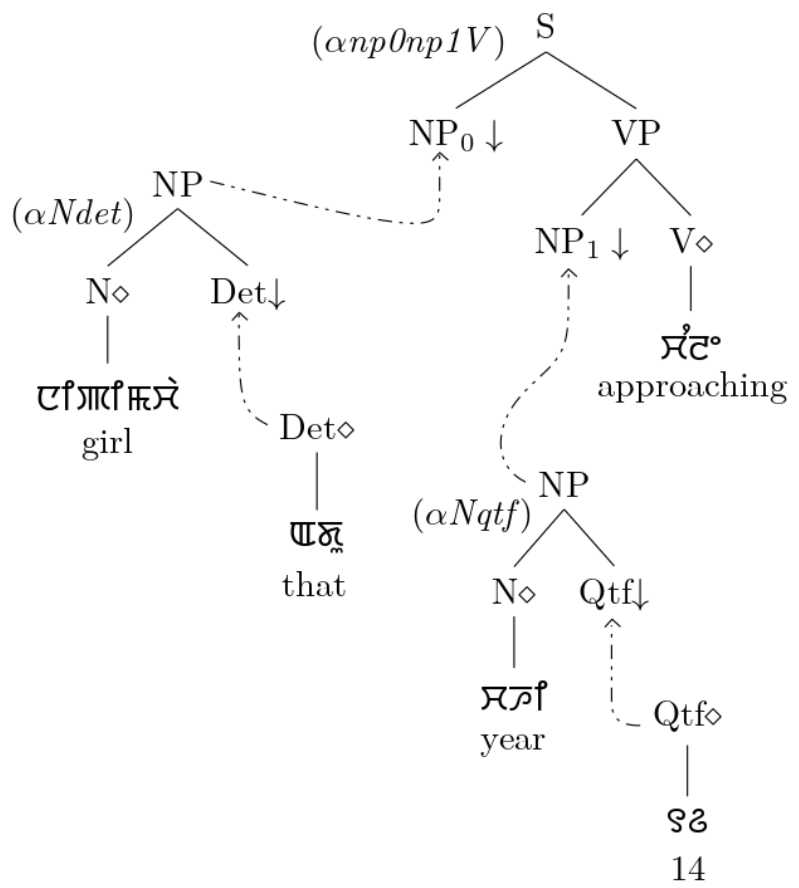

Figure 7. Parse tree formation for example 3

Manipuri sentences with ditransitive verbs contain a subject and two objects: a direct and an indirect object [3, 11]. In general, the direct object normally succeeds the indirect object, but an interchange in their positions is also possible [3]. We represent such sentences using the initial tree (anp0np2np1V) shown in Fig. 5. One such sentence is example 9 and its respective parse tree is shown in Fig. 9.

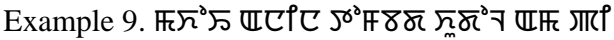

[mək ${ }^{\mathrm{h}}$ oj əninə] $\mathrm{NP}_{0}$ [tombədə] $\mathrm{NP}_{2}\left[\mathrm{k}^{\mathrm{h}} \mathrm{udol}\right.$ əmə] $\mathrm{NP}_{1}$ pilV

The two of them give Tomba a gift.

\subsection{Auxiliary Tree for Verb Modification}

Adverbs, in Manipuri, always precede the verb that is being modified. Theoretically, there can be an infinite number of adverbs modifying a verb [9]. We achieve verb modification through the use of auxiliary tree $(\beta A D V v)$ shown in Fig. 8. As an example, the verb "रेणn modified using the adverb "र्रेमए" (jamnə) as illustrated in Fig. 10.

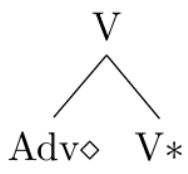

$$
(\beta A D V v)
$$

Figure 8. Auxiliary tree for verb modification

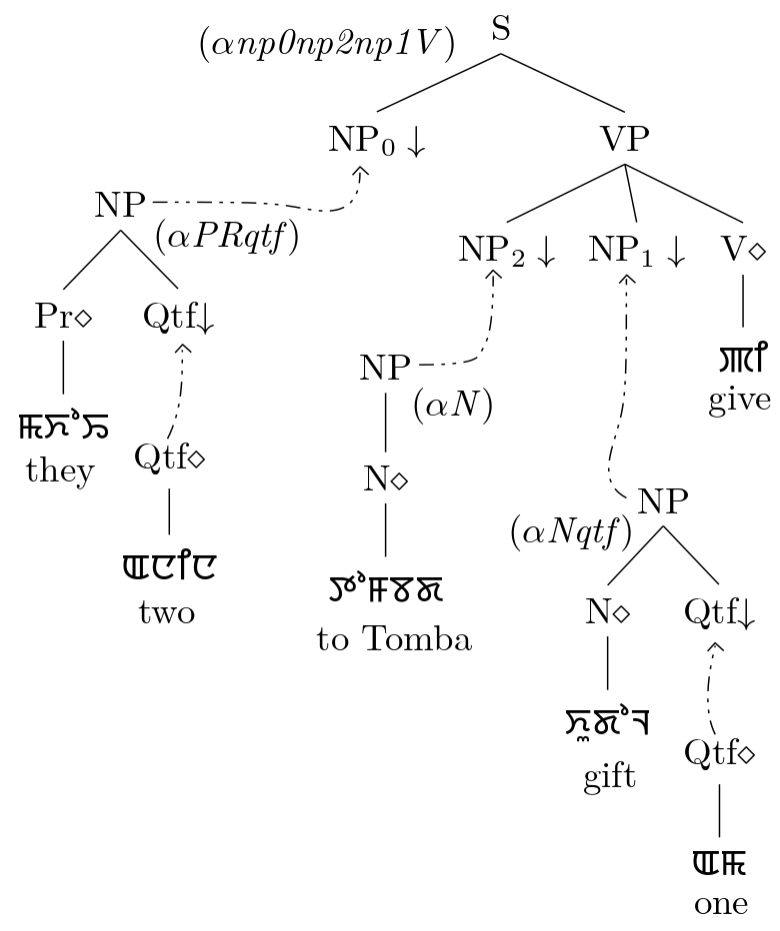

Figure 9. Parse tree formation for example 9

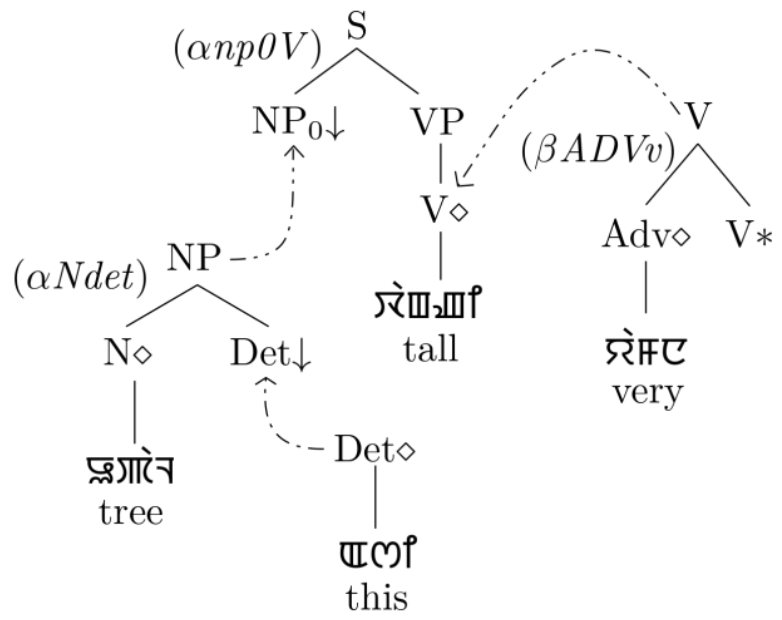

Figure 10. Modification process of verb "रेषس in example 8 using the adverb "र्रेमए" (jamnə)

\section{ELEMENTARY TREES FOR DERIVED MANIPURI SENTENCES}

In Manipuri, sentences are generally derived using coordinate conjunctions or by the process of embedding.

Compound sentences are derived by concatenating two or more sentences using coordinate conjunctions (Conj). Auxiliary trees for compound sentences are represented using the initial tree $\left(\alpha_{s} C O N J s\right)$ shown in Fig. 11. Example 10 illustrates a compound sentence formed by conjoining two simple sentences using the coordinate conjunction (Conj)

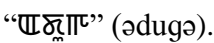




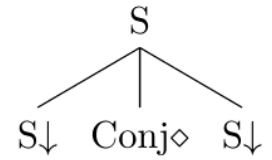

$(\alpha s C O N J s)$

Figure 11. Initial tree for compound sentences

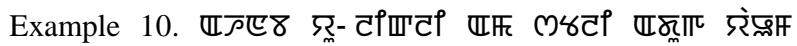

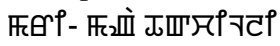

[əhənbə ju-likli əmə sətli]S ədugəlConj [jəum məxi-məna $\mathrm{t}^{\mathrm{h}}$ əkcilli]S

A new wine bottle is pulled out and four-five mouthfuls are drunk.

Complex sentences in Manipuri are formed by embedding one or more sentence within another sentence [12]. Only one of the sentence acts as the main clause (ClMain) and the remaining become subordinate clauses (ClSub). Subordinate clauses always precede the main clause and are dependent on it [13]. A main clause, on the other hand, can stand alone and act as a complete sentence. Subordinate clauses can be further divided into nominal, adverbial and sentential clauses.

Nominal clauses are formed by nominalizing the verb of a sentence that is to be embedded using the nominalizer $-\pi / \pi \sim-8$ (-pə -bə) as a suffix of the verb [9]. The verb, thus nominalized, takes the form of a verbal noun and may also occur with a case marker suffixed to it. Nominal clause generally helps in clarifying the noun of the main clause that follows, thus taking the form of a relative clause. The noun of the main clause, thus clarified, becomes the head of the relative clause and is known as the relativized argument. We represent complex sentences consisting of nominal clauses with the initial trees $(\alpha n p V N s)$, (anpnpVNs) and (anpnpnpVNs), as shown in Fig. 12.
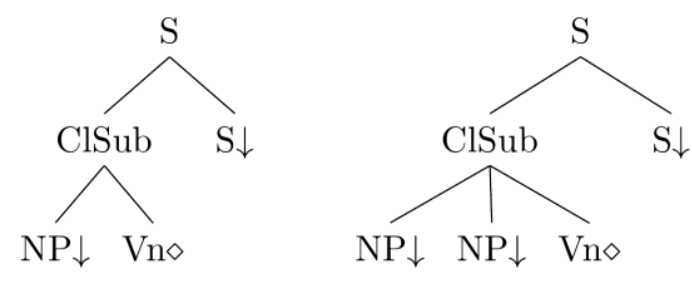

$(\alpha n p V N s)$

$(\alpha n p n p V N s)$

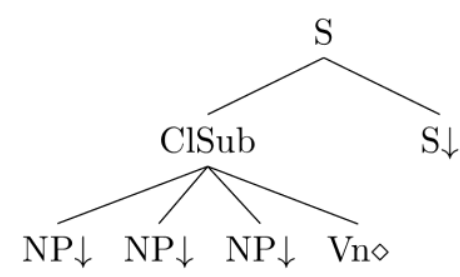

( $\alpha n p n p n p V N s)$

Figure 12. Initial trees for complex sentences with nominalized clauses

An illustration of complex sentence formation with nominal clause in Manipuri is shown in example 11. In the process, the verb "J్m fC $\rho$ " (tumli) of $S_{1}$ is nominalized as "J్m (tumlibə) and then the nominalized sentence $S_{1}$-nom is embedded into $S_{2}$ thus forming complex sentence $S_{3}$. Here, $S_{1}$ takes the form of a subordinate clause and $S_{2}$ become the main clause. The parse tree for example 11(S3) and its formation is illustrated in Fig. 13.

Example 11.

S1:

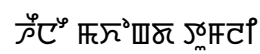

həinəu mək ${ }^{\mathrm{h}}$ ondə tumli

$\mathrm{He} /$ she is sleeping below the mango tree.

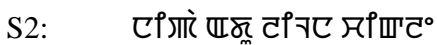

nipa ədu lilnə cikle

The man has been bitten by a snake.

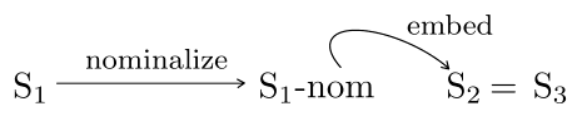

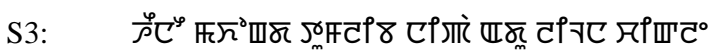

[həinəu mək ${ }^{\mathrm{h}}$ ondə tumli-bəlVn]ClSub [nipa ədu lilnə cikle]ClMain

The man sleeping below the mango tree is bitten by a snake.

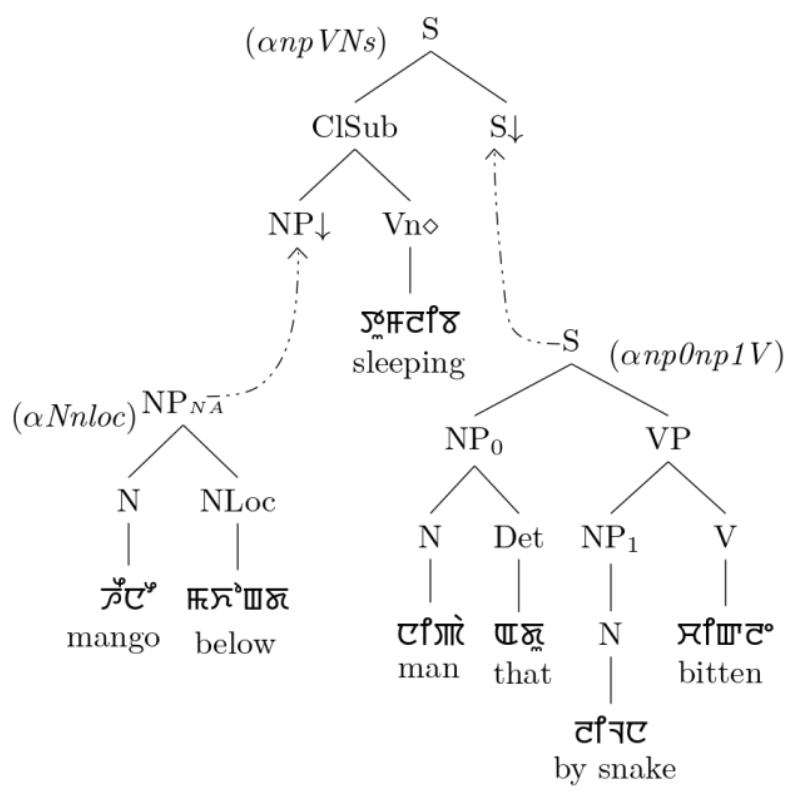

Figure 13. Parse tree formation for complex sentence $S_{3}$ in example 11

An adverbial clause behaves like an adverb and modifies the main clause. Clauses of this type are formed by adding the adverbial suffix $-\Gamma(-n \ni)^{2}$ to the verb of subordinating clause [13]. In order to accommodate the adverbial suffix, the aspectual markers of the verb may also be modified accordingly. We represent complex sentences consisting of adverbial clauses with the initial trees ( $\alpha n p V A s)$, ( $\alpha n p n p V A s)$ and (anpnpnpVAs), as shown in Fig. 14.

An illustration of complex sentence formation with embedded adverbial clause can be seen in example 12. The complex sentence $S_{3}$ is derived by embedding the simple sentence $S_{1}$ in $S_{3}$. In the process, the verb " $\mathrm{d}^{\diamond} \mathrm{W} \boldsymbol{S}$ " ( $\mathrm{t}^{\mathrm{h}}$ oki) of sentence $S_{1}$

\footnotetext{
${ }^{2}$ We use Va to denote verbs ending with the adverbial suffix C (-nə).
} 
undergo morphological change by replacing the aspectual marker "-S" (-i) with the suffix “-- $\int_{m} \Gamma "$ (-tunə), thus converting $S_{1}$ into an adverbial clause. The parse tree for example $12\left(S_{3}\right)$ and its formation is illustrated in Fig. 15.

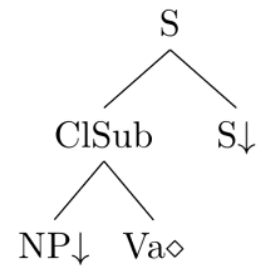

$(\alpha n p V A s)$

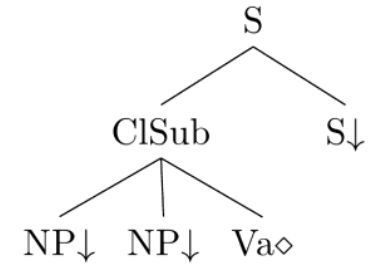

$(\alpha n p n p V A s)$

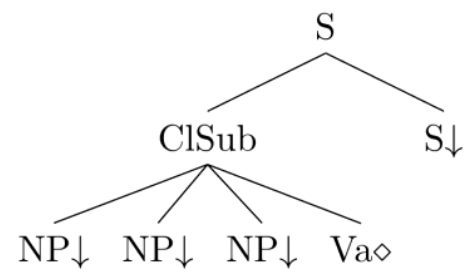

(

Figure 14. Initial trees for complex sentences with adverbial clauses

Example 12.

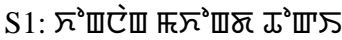

$\mathrm{k}^{\mathrm{h}}$ oynay mək $\mathrm{k}^{\mathrm{h}}$ oydə $\mathrm{t}^{\mathrm{h}} \mathrm{oki}$

$\mathrm{He} /$ she went below the ficus tree.

S2: アో

tombədu yaihak leplui

Tomba stand for some time.

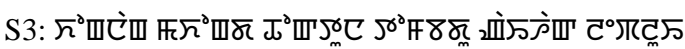

[k $\mathrm{k}^{\mathrm{h}}$ oynay mək ${ }^{\mathrm{h}}$ ondə $\mathrm{t}^{\mathrm{h}}$ oktunəlVa]ClSub [tombədu yaihak leplui]ClMain

Tomba went below the ficus tree and stand there for some time.

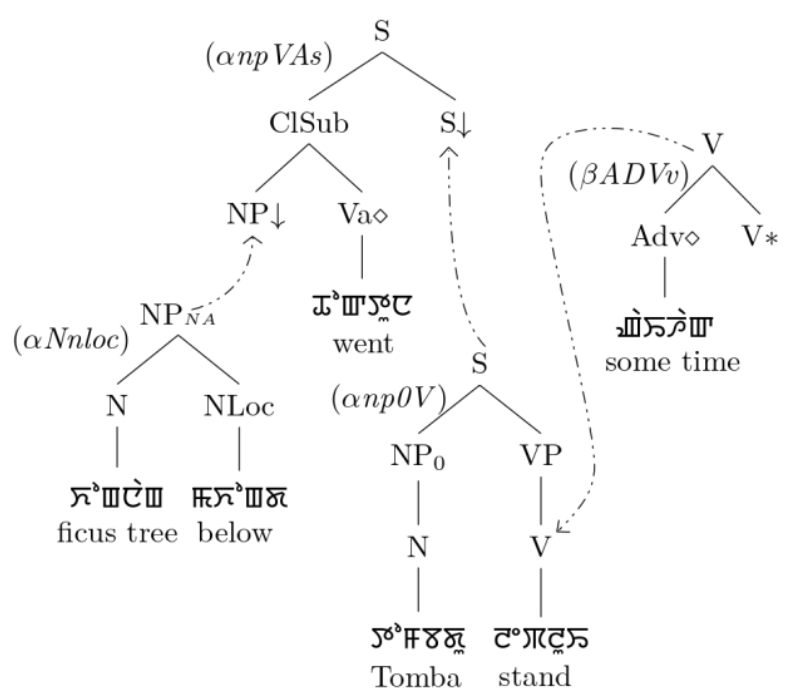

Figure 15. Parse tree formation for example 12( $\left.S_{3}\right)$
Sentential clauses (SClause) are formed by adding

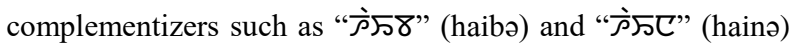
after the verb of the clause being subordinated [13]. They are also known as sentential complements (SCompl) since they form subordinate clauses with a full-fledged sentence [14]. We represent complex sentences formed with the help of sentential clauses using the initial tree ( $\alpha S S C O M P L s)$ shown in Fig. 16.

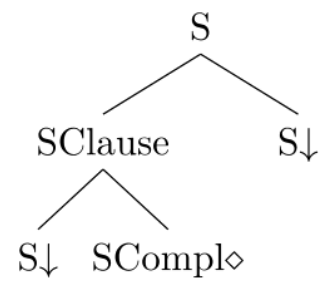

( $\alpha s S C O M P L s)$

Figure 16. Initial trees for complex sentences with sentential clauses

Examples 13 and 14 are two complex sentences formed by using the sentential complementizers " $\bar{j} 58$ " (haibə) and “六らट" (hainə) respectively. The formations of parse trees for these two sentences are shown in Fig. 17 and Fig. 18 respectively.

Example 13. ट९лां ய

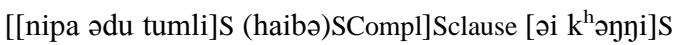

I know that the man is sleeping.

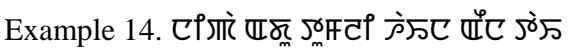

[[nipa ədu tumli]S (hainə)Scompl]SClause [əina tai]S

I heard that the man is sleeping.

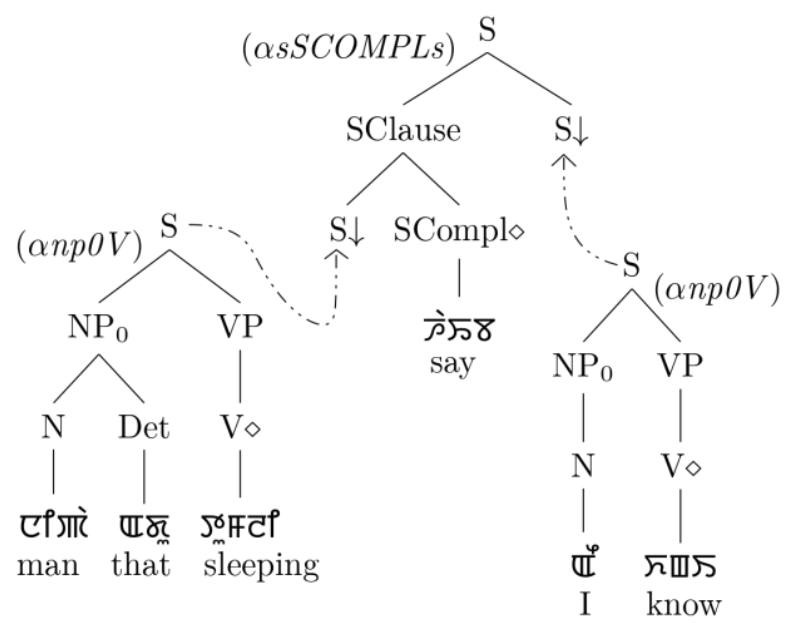

Figure 17. Parse tree formation for example 13 


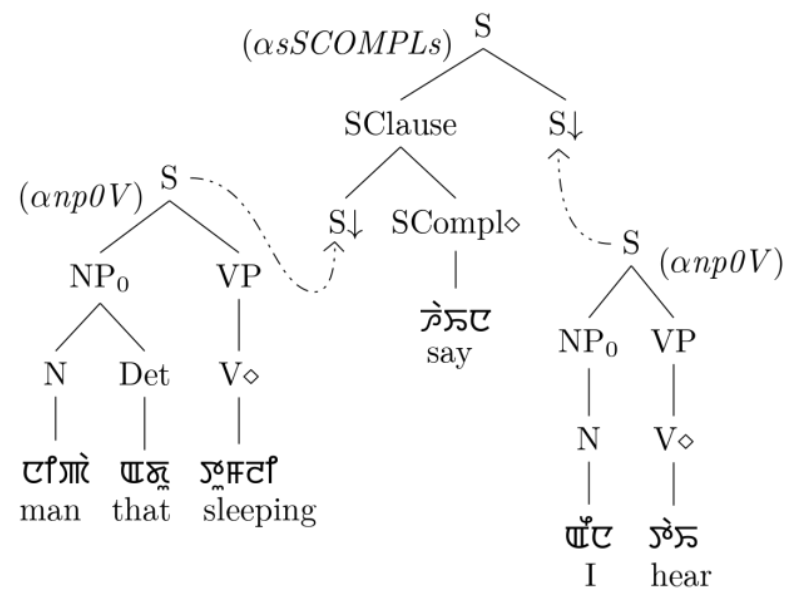

Figure 18. Parse tree formation for example 14

\section{CONCLUSION}

We introduced a TAG formalism for Manipuri language, which is low in resource and for which data-driven parsing is not viable due to non availability of Treebanks. We extensively analyzed the language structure and formulate the Manipuri TAG formalism. The grammar covers structures of Manipuri phrases, clauses, basic sentences, as well as derived sentences. Our grammar can be used for creating a Manipuri parser and would be extremely helpful for creating a Treebank for Manipuri.

\section{REFERENCES}

[1] A. K. Joshi, L. S. Levy, and M. Takahashi, "Tree Adjunct Grammars", Journal of Computer and System Sciences, vol. 10, no. 1, (1975), pp.136-163.

[2] Y. Schabes, A. Abeillé, and A. K. Joshi, "Parsing Strategies with 'Lexicalized' Grammars: Application to Tree Adjoining Grammars", Technical Reports (CIS), (1988).

[3] C. Y. Singh, "Manipuri Grammar", Rajesh Publications, New Delhi, India, (2000).

[4] L. N. Singh and U. Sharma, "Modelling the Syntax of Manipuri: a Tibeto-Burman Language", Unpublished MTech dissertation, Tezpur University, Assam, India, (2012).

[5] Y. Nirmal and U. Sharma, "Problems and Issues in Parsing Manipuri Text”, Edited J. Mandal, G. Saha, D. Kandar, and A. Maji, Proceedings of the International Conference on Computing and Communication Systems, Lecture Notes in Networks and Systems, Springer, Singapore, vol. 24, (2018), pp. 393-401, https://doi.org/10.1007/978-981-10-6890-4 38.

[6] Y. Nirmal and U. Sharma, "A Grammar-Driven Approach for Parsing Manipuri Language", Edited B. Deka, P. Maji, S. Mitra, D. Bhattacharyya, P. Bora, and S. Pal, Pattern Recognition and Machine Intelligence (PReMI), Lecture Notes in Computer Science, Springer, Cham, vol. 11942, (2019), pp. 267-274, https://doi.org/10.1007/978-3-030-34872-4_30.

[7] B. Sarangthem and L.L. Singh, "Noun Phrase in Manipuri (Meiteiron) as a Data Structure for Computational processes", http://www.academia.edu/download/36391237/Noun_ph rase structure of Meiteilon.pdf.
[8] P. M. Devi, "Manipuri Grammar", Unpublished PhD Thesis, Savitribai Phule Pune University, Pune, India, (1979).

[9] S. L. Chelliah, "A Grammar of Meithei", Walter De Gruyter, Berlin, (1997).

[10] J. A. Matisoff, S. P. Baron and J. B. Lowe, "Languages and Dialects of Tibeto-Burman", https://stedt.berkeley.edu/pubs_and_prods/STEDT_Mon ograph2_Lgs-Dialects-TB_with-orig-article.pdf.

[11] T. Poudel, "Ergative/Nominative Alternations in Manipuri Intransitive Constructions", http://citeseerx.ist.psu.edu/viewdoc/download?doi=10.1. $1.705 .9879 \&$ rep $=$ rep $1 \&$ type $=$ pdf.

[12] P. C. Thoudam, "A Grammatical Sketch of Meiteiron", Unpublished PhD Thesis, Jawaharlal Nehru University, New Delhi, India, (1980).

[13] S. I. Singh, "Manipuri Clause Structure" Unpublished $\mathrm{PhD}$ Thesis, Manipur University, Imphal, India, (2013).

[14] D. N. S. Bhat and M. S. Ningomba, "Manipuri Grammar", Central Institute of Indian Languages, Mysore, (1997). 